\title{
Matthew Wilson, New Lines
}

\author{
Review by Dillon Mahmoudi
}

Matthew W. Wilson, New Lines: Critical GIS and the Trouble of the Map (Minneapolis: University of Minneapolis Press, 2017).

In New Lines Matthew Wilson tackles one of cartography and Geographic Information Science's (GIS) most glaring struggles: the blurring between object and subject. With the seemingly increasing speed at which digital technologies in general, and mapping technologies specifically, were both developed and disseminated, new forms of understanding challenged the existing understanding of mapping. What was GIS? More importantly, wh was left of the study of maps, mapmaking, and GIS after these snowballing technocultural shifts? It is at this critical juncture that Wilson steps in.

The charge of this book is to examine these shifts as they challenge and change our focus, by examining pervasive technologies that are also largely opaque. This is my call to take responsibility for digital mapping in ways that do not deactivate scholarship but make it more resonate. $(\mathrm{x})$

New Lines is an instant classic alongside contemporary critical works from scholars such as Sarah Elwood, Rob Kitchin, Agnieszka Leszczynski, Nadine Schurmann, and Stephen Graham which expand many of the cartographic provocations from scholars like JB Harley, William Bunge, Gunna Olsson, and even Neil Smith among others. With the working concept that the map is an event and armed with the charge to make mapping more public and resonate, Wilson invokes Deleuze and Guattari's lines of flight to identify and develop existing fractures and future directions of critical Gl For readers of this journal, Wilson's problematization of subject, object, and representation should make clear the intention to make the meaning of mapping malleable as one way to combat the tendency to turn mapping into a rigid, soulless, technoscientific practice. In doing so, Wilson identifie: "five fractures or five potential lines of flight that consolidate as well as radiate, that stay with the trouble" (22) toward a critical-, counter-, feminist-, heterodox-GIS that might be.

The book is organized into an introduction, five substantive chapters each featuring a fracture, and a concluding chapter, conducive of a coherent, readable, and direct message. While acknowledging that there are many fractures, the book focuses on the five which Wilson argues are both the most important and the most urgent. These are: (1) criticality, (2) digitality, (3) movement, (4) attention, and (5) quantification. Each chapter successfl traces the origins of each fracture, building toward the potential of new lines of flight. In the discussion of criticality, Wilson reframes the current criti movement using the quantification of geography movement in the 1960s and the critical human geography movement of the 1980s. Using this long history of what is critical cartography, this chapter reminds us that the struggle of "critical" is always old and always new. Here, the book posits that the fetish for faddish visuals, like infographics, mask the casual mechanisms which produce the outcomes that are being communicated,

necessitating the continued need for criticality. The third chapter addresses digitality and the lasting impact of the Laboratory for Computer Graphic at Harvard University's Graduate School of Design. This chapter is destined to be required reading in GIS courses, as it traces the successes and failures of communicating via maps while acknowledging the inherent problems in abstraction and representation - or how to lie with maps. The fou chapter brings a new understanding of both physical and affective movement. Using Doreen Massey's work on time to problematize the static map and the focus on design, this chapter artfully argues for a cartography which communicates experience and way the world is represented. The fifth chapter shows how the attention economy adversely impacts community groups fighting for their voice to be heard. Building from Bernard Stiegler, we see how maps move and direct attention, "captivating and motivating thought and action" (114), making obvious the importance of what gets mapped and who decides what to map. The sixth chapter focuses on the commodification of quantified geospatial technologies and data, detailing the quantified-self movement and smart city discourse. Understanding quantification as interoperable system of geospatial data and data exchange we see how a location-aware future serves to commodify everyday life under the spectacle. The last chapter returns to the idea that a map is an eve and what that might mean in how, why, and in what way, we make maps.

To think the map as an event is to introduce a series of pedagogical movements, to motivate a mapping that is beyond effectivity and toward affectivity... These breakages collude and resist distinction. Neither criticality nor digitality solely binds cartographic thought and action. Movement-attention-quantification occur as differences of quality along a continuity of relations: new lines in the location-aware future. Make slow maps. Tinker and fail. (140)

It would be too easy here to complain that the concluding chapter, barely seven pages long, doesn't provide the reader with enough direction to internalize the fractures that were painstakingly excavated and operationalize the new lines that are levied at the reader. Such a critique would miss that a longer conclusion would run counter to the purpose of the book. The book acts as a manifesto for other mapmakers to produce many new lin - sometimes competing, sometimes complementary, and sometimes agnostic. To provide further direction might create a form that was at once rigi setting the groundwork for capture into technoscientific servitude.

Still, the book makes contributions which left the reader wanting at the end. Figure 1 in the book highlights four provocations in the tensions betwee (1) using GIS in radical ways and (2) situating GIS practices. This illustrative example sets the groundwork for conversation for the rest of the introduction, and even the basis for the fractures, but an explicit return to these tensions in the conclusion would have been useful to illustrate their continuing force on potential new lines. Further, the book uses significant archival research to understand cartographic fractures. While the book 
contextualizes these histories, one cannot ignore situating them within other complementary disciplines or their male dominated environments - the very ones which brought the "trouble of the map" addressed in the beginning of the book. In places, these are referenced, but a lengthier discussior here is simply a matter of space in the book despite being important in the intertwined history of the digital map.

The book is an important provocation for any mapmaker, cartographer, and spatial thinker. Ultimately, the book is a required read - even if only for th history alone - for any map user. As a whole, the book simultaneously makes serious theoretical advances while serving as a manifesto for mapmaking practice. Each fracture chapter provides glimmers of possibility for a new critical GIS and generate new insights into, as Wilson says, "how we got here." The individual substantive chapters are suitable for reading by themselves or in groups, lending themselves to the classroom. Tr well written and heavily researched book is sure to be referenced for decades as a call to action in a new era of maps. After all, a single point does $r$ form a line.

\section{Cite this Review}

https://doi.org/10.20415/rhiz/034.r02

RHIZOMES ISSN 1555-9998 $\star 230$ East Hall Bowling Green State University Bowling Green, OH 43403

Editors: Ellen Berry and Carol Siegel. Reviews editor: Craig J. Saper. Technical editor: Helen J Burgess 